JURNAL NOMINAL / VOLUME VI NOMOR 1 / TAHUN 2017

\title{
PENGARUH BYSTANDER EFFECT DAN WHISTLEBLOWING TERHADAP TERJADINYA KECURANGAN LAPORAN KEUANGAN
}

\author{
Nur Asiah \\ Program Studi Akuntansi Fakultas Ekonomi Universitas Negeri Yogyakarta \\ Email:nurasiah29@gmail.com \\ Dhyah Setyorini, M.Si.,Ak. \\ Staf Pengajar Jurusan Pendidikan Akuntansi Universitas Negeri Yogyakarta
}

\begin{abstract}
Abstrak : Pengaruh Bystander Effect Dan Whistleblowing Terhadap Terjadinya Kecurangan Laporan Keuangan. Penelitian ini bertujuan untuk mengetahui: (1) Pengaruh bystander effect terhadap terjadinya kecurangan laporan keuangan. (2) Pengaruh whistleblowing terhadap terjadinya kecurangan laporan keuangan. (3) Pengaruh bystander effect dan whistleblowing secara simultan terhadap terjadinya kecurangan laporan keuangan. Penelitian ini adalah penelitian eksperimen dengan menggunakan desain eksperimen kuasi (quasi experiment) yaitu desain faktorial 2x2. Sampel penelitian adalah mahasiswa Program Studi Akuntansi Fakultas Ekonomi Universitas Negeri Yogyakarta sebanyak 64 mahasiswa. Instrumen yang digunakan yakni kuesioner dan kasus fraud. Hipotesis penelitian diolah menggunakan alat uji statistik two ways ANOVA. Hasil pertama penelitian ini adalah bystander effect berpengaruh positif terhadap terjadinya kecurangan laporan keuangan dengan nilai signifikansinya 0,000 . Whistleblowing berpengaruh negatif terhadap terjadinya kecurangan laporan keuangan dengan nilai signifikansinya 0.000. Bystander Effect diinteraksikan dengan whistleblowing hasilnya tidak berpengaruh signifikan terhadap terjadinya kecurangan laporan keuangan dengan nilai signifikasinya 0.411 .
\end{abstract}

Kata kunci : bystander effect, whistleblowing, kecurangan laporan keuangan

Abstract : The Effect Bystander Effect And Whistleblowing On The Occurrence Of Cheating Financial Statements. This research aims to know the: (1) influence of bystander effect against the onset of the financial statement fraud. (2) the influence of whistleblowing against financial statement fraud. (3) the influence of the bystander effect and whistleblowing simultaneously against the occurrence of the cheating financial report. This research is an experimental research using experimental design quasi (quasi experiment) that is $2 \times 2$ factorial design. The research sample is a student of economic faculty of Accounting Studies Program, Yogyakarta State University of as many as 64 students. The instruments used, i.e. the questionnaires and cases of fraud. Research hypothesis using the tools of statistical tests two ways ANOVA. The first result of this research was the bystander effect gave a positive effect against the onset of the financial statement fraud with the value of their significance 0.000. Whistleblowing gave negative effect against the onset of financial statement fraud with the value 0000 their significance. Bystander Effect interaction with whistleblowing result has no effect against the onset of significant financial statement fraud with a significance value of 0411.

Keywords : bystander effect, whistleblowing, financial statements fraud

\section{PENDAHULUAN}

$\begin{array}{ccr}\text { Setiap } & \text { perusahaan dalam } \\ \text { menjalankan aktivitas usahanya } \\ \text { membutuhkan informasi keuangan dalam }\end{array}$ berinteraksi dengan berbagai pihak.

Informasi keuangan merupakan suatu

bahasa bisnis yang dapat dimengerti oleh

semua pihak yang terkait, dan bahasa 


\section{JURNAL NOMINAL / VOLUME VI NOMOR 1 / TAHUN 2017}

bisnis yang biasa digunakan disebut akuntansi. Hasil dari proses akuntansi berupa laporan keuangan yang digunakan harus dapat menjawab kebutuhan umum para pemakainya. Laporan keuangan yang merupakan informasi penting bagi perusahaan maupun pihak lain yang membutuhkan menjadi rentan akan adanya kecurangan (fraud).

Kecurangan laporan keuangan (financial statement fraud) bisa dilakukan oleh manajer dan karyawan berupa kasus kecurangan financial. Dalam memberikan solusi terhadap kasus-kasus kecurangan dan kelemahan dalam prosedur pendeteksian kecurangan di dunia, American Institute Certified Public Accountant (AICPA) menerbitkan Statement of Auditing Standards No. 99 (SAS No. 99) mengenai Consideration of Fraud in a Financial Statement Audit pada Oktober 2002 (Skousen et al., 2009). Salah satu metode yang dapat mengukur kecurangan laporan keuangan adalah earnings management. Hal tersebut didasarkan pada pernyataan Rezaee (2002) bahwa financial statement fraud berkaitan erat dengan tindakan manipulasi laba yang dilakukan oleh manajemen.

Tindakan yang dilakukan manajemen tersebut dipengaruhi oleh perilaku yang ada pada setiap manusia, kemudian berkembanglah akuntansi keperilakuan. Perilaku manusia ini yang memengaruhi data akuntansi menjadi rentan akan kecurangan. Kecurangan ini terjadi karena adanya efek pengamat (bystander effect), yaitu seseorang yang mengetahui adanya tindak kecurangan tetapi memilih diam dan dalam dirinya sengaja membiarkannya atau tidak ingin terlibat dalam kasus tersebut, yang dapat membuat posisi dirinya bekerja akan terganggu. Salah satu cara mencegah pelanggaran akuntansi sehingga dapat mengembalikan kepercayaan masyarakat adalah dengan melakukan whistleblowing. Pentingnya whistleblowing dalam perusahaan akan bertindak sebagai pemberi peringatan ataupun saksi atas seseorang yang melakukan kecurangan laporan keuangan. Penelitian sebelumnya yang dilakukan oleh Sharon Naomi (2015) yang menggunakan penerapan whistleblowing system dan dampaknya terhadap fraud. Dari hasil penelitian tersebut membuktikan bahwa dengan adanya penerapan whistleblowing system ini dapat mengurangi atau meminimalisir kasus fraud yang terjadi.

Berdasarkan uraian di atas, dapat dilihat bystander effect dan whistleblowing sangat penting terhadap perilaku manajer dan karyawan untuk melakukan kecurangan laporan keuangan. Penulis tertarik untuk melakukan kajian serta penelitian lebih lanjut lagi untuk melihat persepsi mahasiswa mengenai 


\section{JURNAL NOMINAL / VOLUME VI NOMOR 1 / TAHUN 2017}

"Pengaruh Bystander Effect Dan Whistleblowing terhadap Terjadinya Kecurangan Laporan Keuangan (Studi Eksperimen dengan Kasus Fraud Pada Mahasiswa Program Studi Akuntansi Fakultas Ekonomi Universitas Negeri Yogyakarta)".

Menurut Association of Certified Fraud Examiners (ACFE) kecurangan (fraud) didefinisikan sebagai tindakan penipuan atau kekeliruan yang dibuat oleh seseorang atau badan yang mengetahui bahwa kekeliruan tersebut dapat mengakibatkan beberapa manfaat yang tidak baik kepada individu atau entitas atau pihak lain. Menurut Irham Fahmi (2012: 22), "Laporan keuangan adalah suatu informasi yang menggambarkan kondisi suatu perusahaan, dimana selanjutnya itu akan menjadi suatu informasi yang menggambarkan tentang kinerja suatu perusahaan". American Institute Certified Public Accountant (1998), financial statement fraud adalah tindakan yang disengaja atau kelalaian yang berakibat pada salah saji material yang menyesatkan laporan keuangan.

Hasil penelitian yang dilakukan oleh Norbarani (2012) untuk mendeteksi kecurangan laporan keuangan berdasarkan analisis fraud triangle yang diadopsi dalam SAS No. 99. Teori fraud triangle yang dikemukakan oleh Cressey (1953) menyatakan bahwa terdapat tiga kondisi yang selalu hadir dalam setiap kejadian fraud. Ketiga kondisi tersebut yaitu, pressure, opportunity dan rationalization. Kecurangan pada laporan keuangan atau financial statement fraud dalam penelitian ini diproksikan dengan earnings management.

Bystander Effect adalah fenomena sosial di bidang psikologi dimana semakin besar jumlah orang yang ada di sebuah tempat kejadian, akan semakin kecil kemungkinan orang-orang tersebut membantu seseorang yang sedang berada dalam situasi darurat di tempat kejadian itu (Sarwono, 2009). Peneliti psikologi sosial seperti John Darley dan Mark Levin menggarisbawahi dua kemungkinan (di antara banyak kemungkinan lain): pengaruh dari bystander lain dan diffusion of responsibility.

Kecurangan ini terjadi karena adanya efek pengamat (bystander effect), yaitu seseorang yang mengetahui adanya tindak kecurangan tetapi memilih diam dan dalam dirinya sengaja membiarkannya atau tidak ingin terlibat dalam kasus tersebut, yang dapat membuat posisi dirinya bekerja akan terganggu. Indikator dalam bystander effect (Sarwono, 2009) sebagai berikut: (1) Pengaruh sosial, yaitu pengaruh dari orang lain yang dijadikan sebagai patokan dalam menginterpretasi situasi dan mengambil keputusan untuk ikut campur, 


\section{JURNAL NOMINAL / VOLUME VI NOMOR 1 / TAHUN 2017}

seseorang akan ikut campur jika orang lain juga ikut campur; (2) Hambatan bystander, yaitu merasa dirinya dinilai oleh orang lain dan risiko membuat malu diri sendiri karena tindakannya ikut campur yang kurang tepat akan menghambat orang lain untuk ikut campur; (3) Penyebaran tanggung jawab membuat tanggung jawab untuk ikut campur menjadi terbagi karena hadirnya orang lain.

Berdasarkan penelitian Halimah, dkk. (2015) peran bystander terhadap intensitas bullying pada siswa SMP menunjukkan bahwa terdapat pengaruh positif persepsi pada bystander terhadap intensitas bullying. Dalam penelitian ini peneliti menggunakan bystander effect sebagai konsep dasarnya.

\section{$\mathrm{H}_{1}$ : Bystander effect berpengaruh positif terhadap terjadinya kecurangan laporan keuangan.}

Hoffman and Robert (2008) mendefinisikan whistleblowing sebagai suatu pengungkapan oleh karyawan mengenai suatu informasi yang diyakini mengandung pelanggaran hukum, peraturan, pedoman praktis atau pernyataan professional, atau berkaitan dengan kesalahan prosedur, korupsi, penyalahgunaan wewenang atau membahayakan publik dan keselamatan tempat kerja. Whistleblowing adalah pelaporan yang dilakukan oleh anggota organisasi aktif maupun nonaktif mengenai pelanggaran, tindakan ilegal atau tidak bermoral kepada pihak di dalam maupun di luar organisasi (Khan, 2009).

Untuk menjalankan whistleblowing dalam perusahaan dengan menggunakan Whistleblowing System. Sistem ini dibentuk oleh Komite Audit perusahaan dan berdasarkan peraturan OJK Nomor: IX .1.5 yang mewajibkan Komite Audit untuk menangani pengaduan, dan Sarbanes-Oxley Act of 2002 Section 310 tentang Public Company Audit Committee yang mengharuskan Komite Audit untuk menerima, menelaah, dan menindaklanjuti pengaduan yang berkaitan dengan masalah akuntansi, pengendalian internal, dan auditing, dengan tetap menjaga kerahasiaan identitas pelapor. Di dalam Pedoman Whistleblowing System yang diterbitkan KNKG (2008), indikator sistem whistleblowing terdiri dari 3 aspek, yaitu: (1) Aspek struktural, (2) Aspek operasional, (3) Aspek perawatan.

Penelitian yang dilakukan oleh Naomi (2015) untuk mengetahui penerapan whistleblowing system, serta mengetahui dampak penerapan whistleblowing system terhadap fraud. Hasil penelitian menunjukkan bahwa penerapan whistleblowing system di PT Telekomunikasi Indonesia sudah berjalan 
JURNAL NOMINAL / VOLUME VI NOMOR 1 / TAHUN 2017

dengan baik karena adanya penurunan tingkat fraud.

\section{$\mathrm{H}_{2}$ : Whistleblowing berpengaruh negatif terhadap terjadinya}

kecurangan laporan keuangan.

Bystander effect dan

whistleblowing merupakan persepsi yang saling bertentangan, namun dalam dunia nyata persepsi sesorang dalam mengambil keputusan juga dapat dipengaruhi oleh keputusan seseorang sehingga pengaruh bystander effect lebih kuat dibandingkan whistleblowing. Tanggung jawab dalam melaporkan tindakan tidak etis menjadi tersebar dan menjadi bukan prioritas individu dengan adanya penyebaran tanggung jawab inilah sebuah tindakan non etis menjadi pilihan. Persepsi yang dipilih juga merupakan adanya tekanan karena terlalu banyaknya bystander effect menjadi ketidak mampuan seorang whistleblowing dalam melakukan sebuah pengungkapan mengenai suatu informasi yang diyakini mengandung pelanggaran hukum, peraturan, pedoman praktis atau pernyataan professional, atau berkaitan dengan kesalahan prosedur, korupsi, penyalahgunaan wewenang atau membahayakan publik dan keselamatan tempat kerja.

Secara simultan bystander effect dan whistleblowing berpengaruh positif terhadap kecurangan laporan keuangan disebabkan adanya perilaku prososial lebih mendorong adanya kecurangan laporan keuangan tersebut.

H3: Bystander effect dan Whistleblowing berpengaruh positif terhadap terjadinya kecurangan laporan keuangan.

Manfaat dari penelitian ini diharapkan dapat dijadikan sebagai sumber referensi atau rujukan kepada peneliti selanjutnya yang sejenis guna mengembangkan penelitian tentang akuntansi keperilakuan maupun analisis laporan keuangan di lingkungan masyarakat pada umumnya dan mahasiswa pada khususnya.

\section{METODE PENELITIAN}

\section{Jenis Penelitian}

Penelitian ini adalah penelitian eksperimen yang menyebabkan terjadinya suatu peristiwa atau variabel bebasnya dikendalikan oleh peneliti dengan menggunakan desain eksperimen kuasi (quasi experiment) yaitu desain faktorial $2 \times 2$.

\section{Waktu dan Tempat Penelitian}

Penelitian ini akan dilaksanakan di Universitas Negeri Yogyakarta dengan memberikan angket kepada mahasiswa Program Studi Akuntansi Jurusan Pendidikan Akuntansi Fakultas Ekonomi 


\section{JURNAL NOMINAL / VOLUME VI NOMOR 1 / TAHUN 2017}

Universitas Negeri Yogyakarta untuk mendapatkan data. Waktu pelaksanaan penelitian ini adalah Oktober 2016.

\section{Subjek Penelitian}

Populasi pada penelitian ini adalah mahasiswa Program Studi Akuntansi Jurusan Pendidikan Akuntansi Fakultas Ekonomi Universitas Negeri Yogyakarta. Sampel penelitian ini adalah angkatan 2013 untuk reguler kelas A sejumlah 32, kelas B sejumlah 32, sehingga total mahasiswa sejumlah 64. Teknik pengambilan sampel dengan menggunakan cara purposive sampling. Kriteria yang digunakan sebagai koresponden penelitian adalah mahasiswa yang sudah mendapat dan mengambil mata kuliah akuntansi keperilakuan dan analisis laporan keuangan.

\section{Prosedur Eksperimen}

Prosedur penelitian yaitu subjek penelitian yang merupakan responden dibagi menjadi dua kelompok. Untuk lebih menjaga adanya kelompok yang tidak saling berhubungan, peneliti membagi kelompok control untuk kelas B dan kelompok treatment untuk kelas A. Pada kasus A, responden akan setuju dengan pernyataan dari kasus yang ada. Hal tersebut dikarenakan adanya perlakuan bystander effect bagi para pelaku fraud ataupun karyawan yang mendukung fraud. Pada kasus B, responden akan setuju dengan pernyataan dari kasus yang ada. Hal tersebut dikarenakan adanya perlakuan whistleblowing bagi para bukan pelaku fraud ataupun karyawan yang tidak mendukung fraud.

Tabel 1. Desain eksperimen $2 \times 2$

\begin{tabular}{c|c|c}
\multicolumn{3}{c}{ Bystander effect $x$ Whistleblowing) } \\
\hline $\begin{array}{c}\text { Terjadinya } \\
\text { Kecurangan } \\
\text { Kaporan } \\
\text { Keuangan (Y) }\end{array}$ & $\begin{array}{c}\text { Kasus A : } \\
\text { Bystander } \\
\text { Effect } \\
\left(\mathrm{X}_{1}\right)\end{array}$ & $\begin{array}{c}\text { Kasus B: } \\
\text { Whistleblowing } \\
\left(\mathrm{X}_{2}\right)\end{array}$ \\
\hline Control ( $\left.\mathrm{Y}_{1}\right)$ & $\mathrm{X}_{1} \mathrm{Y}_{1}$ & $\mathrm{X}_{2} \mathrm{Y}_{1}$ \\
\hline Treatment ( $\left.\mathrm{Y}_{2}\right)$ & $\mathrm{X}_{1} \mathrm{Y}_{2}$ & $\mathrm{X}_{2} \mathrm{Y}_{2}$ \\
\hline
\end{tabular}

Dari tabel 1 dapat diketahui, responden yang mendapatkan kasus A diberikan perlakuan ada bystander effect $\left(\mathrm{X}_{1} \mathrm{Y}_{1}\right.$ dan $\left.\mathrm{X}_{1} \mathrm{Y}_{2}\right)$. Responden yang mendapat kasus B diberikan perlakuan ada whistleblowing $\left(\mathrm{X}_{2} \mathrm{Y}_{1}\right.$ dan $\left.\mathrm{X}_{2} \mathrm{Y}_{2}\right)$.

\section{Data, Instrumen, dan Teknik}

\section{Pengumpulan}

\section{a) Data}

Teknik

pengumpulan data menggunakan data primer yang diperoleh langsung dari objek penelitian dalam beberapa tahapan eksperimen. Instrumen yang digunakan yakni kuesioner dan kasus fraud. Pada penelitian ini terdapat 3 (tiga) variabel dalam instrumen penelitian yaitu, bystander effect, whistleblowing dan terjadinya kecurangan laporan keuangan. Skala pengukuran yang digunakan dalam 
penelitian ini adalah dengan menggunakan Skala Likert 1-4.

\section{b) Teknik Analisis Data}

Penelitian ini menggunakan uji manipulation check untuk memeriksa seberapa jauh konsep terjadinya kecurangan laporan keuangan dipahami oleh responden. Uji validitas menggunakan uji CFA (confirmatory factor analysis) dengan variabel yang diharapkan memilki nilai Kaiser-MeyerOlkin Measure of Sampling Adequacy (KMO MSA) >0,5. Untuk menguji reliabilitas dalam penelitian ini digunakan koefisien Cronbach's Alpha. Suatu construct atau variabel dikatakan reliabel jika memberikan nilai Cronbach's Alpha $>0,60$. Teknik analisis data dengan statistik deskriptif, pengujian prasyarat (Uji Normalitas dan Uji Varians), dan pengujian hipotesis menggunakan alat uji statistik two ways ANOVA menggunakan General Linear Model untuk mengetahui pengaruh utama dari tiap variabel independen terhadap variabel dependen.

\section{HASIL PENELITIAN DAN PEMBA- HASAN}

\section{Deskripsi Data Penelitian}

Dari jumlah responden sebanyak 64 mahasiswa dibagi menjadi dua kelompok, kelompok control dan kelompok treatment dengan masing-masing kelompok sebanyak 32 mahasiswa. Berikut adalah data deskripsi responden dengan data penelitian:

Tabel 2. Deskripsi Responden dan Data Penelitian

\begin{tabular}{|c|c|c|c|c|}
\hline \multirow[t]{2}{*}{ No } & \multirow[t]{2}{*}{ Kelompok } & \multicolumn{2}{|c|}{ Responden } & \multirow[b]{2}{*}{$\stackrel{\bar{E}}{\bar{\Xi}}$} \\
\hline & & $\begin{array}{c}\text { Angkatan } \\
2013 \\
\text { Kelas B }\end{array}$ & $\begin{array}{c}\text { Angkatan } \\
2013 \\
\text { Kelas A }\end{array}$ & \\
\hline 1 & Control & 32 & - & 32 \\
\hline 2 & Treatment & - & 32 & 32 \\
\hline \multicolumn{4}{|c|}{ Jumlah data yang dapat diolah } & 64 \\
\hline
\end{tabular}

Sumber: Data Primer 2016, diolah

\section{Deskripsi Data Khusus}

a) Statistik Deskriptif Data Demografi Responden

1) Statistik Deskriptif Jenis Kelamin

Statistik deskriptif jenis kelamin hasil analisis data dapat diketahui bahwa responden paling banyak berjenis kelamin perempuan dengan jumlah 33 (52\%), sedangkan responden berjenis kelamin laki-laki berjumlah $31(48 \%)$.

2) Statistik Deskriptif IPK

Statistik deskriptif IPK hasil analisis data dapat diketahui bahwa IPK rata-rata responden 3,01 hingga 4. Nilai IPK responden tertinggi pada 4, sedangkan nilai IPK terendah pada 3,01. Nilai tengah dari IPK responden pada 3,5. Standar deviasi pada data 


\section{JURNAL NOMINAL / VOLUME VI NOMOR 1 / TAHUN 2017}

responden berada pada 0,29011 dan varians berada pada 0,084 .

\section{b) Statistik Deskriptif Variabel}

Statistik deskriptif variabel data penelitian kasus memperlihatkan distribusi mean terjadinya kecurangan laporan keuangan (FIN) pada variabel control dan treatment bahwa mean FIN lebih besar pada kelompok treatment $(3,4062)$ dibandingkan pada kelompok control $(3,1562)$.

Statistik deskriptif variabel FIN, BYS, dan WHI memperlihatkan distribusi mean terjadinya kecurangan laporan keuangan (FIN) pada variabel BYS dan WHI. Tabel 4.5 menunjukkan bahwa mean FIN lebih tinggi pada kelompok BYS tinggi $(26,10>23,54)$ dan sebaliknya mean FIN lebih rendah pada kelompok WHI tinggi $(35,84<39,26)$, sedangkan mean FIN lebih tinggi untuk interaksi antara BYS*WHI $(64,42>20,37)$.

\section{Uji Validitas dan Reliabilitas}

Berdasarkan Tabel 12., nilai KMO MSA (Kaiser-Mayer-Olkin Measure of Sampling Adequacy) menunjukkan nilai $>0,5$ dengan signifikansi 0,000 , yang artinya valid. Ada beberapa pernyataan yang tidak valid yang nilai factor loadings di bawah 0,4 sehingga pertanyaan tersebut harus dibuang. Pernyataan untuk variabel Terjadinya Kecurangan Laporan

Keuangan yang dibuang adalah pernyataan nomor $3,12,14,16,17$, dan 21. Pernyataan untuk variabel bystander effect yang dibuang adalah pernyataan nomor 2 . Pernyataan untuk variabel whistleblowing yang dibuang adalah pernyataan nomor 4 . Setelah dilakukan uji validitas, kemudian dilakukan uji reliabilitas. Tabel 12. menunjukkan nilai Cronbach's Alpha $>0,6$, yang artinya reliabel.

Tabel 3. Hasil Uji Validitas \& Reliabilitas

\begin{tabular}{ccccc}
\hline $\begin{array}{c}\text { Vari } \\
\text { abel }\end{array}$ & $\begin{array}{c}\text { KMO } \\
\text { MSA }\end{array}$ & Sig. & $\begin{array}{c}\text { Factor } \\
\text { Loadings }\end{array}$ & $\begin{array}{c}\text { Cronbach's } \\
\text { Alpha }\end{array}$ \\
\hline FIN & 0.804 & 0.000 & $.591-.807$ & 0.931 \\
\hline BYS & 0.838 & 0.000 & $.126-.992$ & 0.897 \\
\hline WHI & 0.852 & 0.000 & $.380-.925$ & 0.924 \\
\hline
\end{tabular}

Sumber: Data Primer 2016, diolah

\section{Manipulation Check}

Tabel 4. Hasil Uji Manipulation check

\begin{tabular}{ccccccc}
\hline & $\mathrm{N}$ & Min & $\begin{array}{c}\text { Ma } \\
\mathrm{x}\end{array}$ & Mean & $\begin{array}{c}\text { Std. } \\
\text { Deviat } \\
\text { ion }\end{array}$ & $\begin{array}{c}\text { Vari } \\
\text { ance }\end{array}$ \\
\hline \multirow{2}{*}{$\mathrm{MC}$} & 6 & 2 & 4 & $\begin{array}{c}3.281 \\
2\end{array}$ & $\begin{array}{c}0.5764 \\
9\end{array}$ & $\begin{array}{c}0.33 \\
2\end{array}$ \\
\hline
\end{tabular}

Sumber: Data Primer 2016, diolah

Dalam penelitian ini nilai mean score-nya mencapai 3,28 yang artinya responden dinilai memahami konsep terjadinya kecurangan laporan keuangan.

\section{Hasil Pengujian Prasyarat}

Tabel 5. Hasil Uji Normalitas

\begin{tabular}{ccc}
\hline & Asymp Sig. & Keterangan \\
\hline FIN & 0.34 & Distribusi Normal \\
\hline \multicolumn{2}{c}{ Sumber: Data Primer } & 2016, diolah
\end{tabular}


Uji normalitas menunjukkan hasil untuk variabel terjadinya kecurangan laporan keuangan. Hasilnya menunjukkan bahwa nilai signifikasi (Asymp. Sig) >0,05 $(0,34)$, yang artinya data berdistribusi normal.

Tabel 6. Hasil Uji Varians

\begin{tabular}{cc}
\hline $\begin{array}{c}\text { Levene's Test } \\
\text { (Sig.) }\end{array}$ & Keterangan \\
\hline 0.090 & $\begin{array}{c}\text { Varians antar kelompok } \\
\text { sama }\end{array}$ \\
\hline
\end{tabular}

Sumber: Data Primer 2016, diolah

Nilai signifikasi dari Levene's Test menunjukkan >0,05 $(0,090)$, yang artinya varians kelompok kategori sama.

\section{Hasil Pengujian Hipotesis}

Setelah ketiga asumsi terpenuhi, dilakukan pengujian hipotesis menggunakan General Linier Model. Tabel berikut ini menunjukkan hasil pengujian hipotesis.

Tabel 7. Hasil Uji Two Way ANOVA dengan General Linier Model

\begin{tabular}{ccc}
\hline Variabel & Sig. & Keterangan \\
\hline BYS & 0.000 & H1 didukung \\
WHI & 0.000 & H2 didukung \\
BYS*WHI & 0.411 & H3 tidak didukung \\
FRCASE*BYS & 0.000 & Terjadi interaction effect \\
FRCASE*WHI & 0.000 & Terjadi interaction effect \\
\hline
\end{tabular}

Sumber: Data Primer 2016, diolah

\section{Bystander Effect berpengaruh}

signifikan terhadap terjadinya kecurangan laporan keuangan karena nilai signifikansinya $<0,05(0,000)$ sehingga $\mathrm{H}_{1}$ didukung. Whistleblowing berpengaruh signifikan terhadap terjadinya kecurangan laporan keuangan karena nilai signifikansinya $<0,05(0,000)$ sehingga $\mathrm{H}_{2}$ didukung. Jika bystander effect diinteraksikan dengan whistleblowing hasilnya tidak berpengaruh signifikan terhadap terjadinya kecurangan laporan keuangan karena nilai signifikasinya $>0,05$ $(0,411)$ sehingga $\mathrm{H}_{3}$ tidak didukung. Ketika variabel bystander effect diinteraksikan dengan FRCASE hasilnya berpengaruh signifikan terhadap FIN karena nilai signifikasinya $<0,05(0,000)$. Variabel whistleblowing diinteraksikan dengan FRCASE hasilnya berpengaruh signifikan terhadap FIN karena nilai signifikasinya $<0,05(0,000)$.

\section{Pembahasan}

\section{a) Pembahasan Hipotesis 1}

Hasil pengujian yang dilakukan menunjukkan bahwa $\mathrm{H}_{1}$ didukung karena bystander effect berpengaruh positif terhadap terjadinya kecurangan laporan keuangan. Nilai signifikasi pada hasil pengujian adalah 0,000 . Nilai signifikansi pada hipotesis $<0,05$, yang artinya adanya seorang bystander memberikan dampak tingginya kecurangan laporan keuangan. Nilai mean terjadinya kecurangan laporan keuangan secara signifikan lebih tinggi 


\section{JURNAL NOMINAL / VOLUME VI NOMOR 1 / TAHUN 2017}

untuk kelompok BYS tinggi daripada kelompok BYS rendah maka $\mathrm{H}_{1}$ didukung $\quad(26,10>23,54) . \quad$ Hasil penelitian ini mendukung penelitian yang dilakukan A Ivan Sudibyo (2010) yang menyatakan bahwa terdapat pengaruh bystander bullying terhadap tindakan prososial.

Dengan demikian maka Mahasiswa Akuntansi UNY akan lebih bertindak bystander karena adanya seorang bystander dilingkungannya sehingga menjadikan terjadinya kecurangan laporan keuangan semakin tinggi jika menerapkan bystander effect.

\section{b) Pembahasan Hipotesis 2}

Hasil pengujian yang dilakukan menunjukkan bahwa $\mathrm{H}_{2}$ didukung karena whistleblowing berpengaruh positif terhadap terjadinya kecurangan laporan keuangan. Nilai signifikasi pada hasil pengujian adalah 0,000 Nilai signifikansi pada hipotesis $<0,05$, yang artinya adanya seorang whistleblower memberikan dampak rendahnya kecurangan laporan keuangan. Nilai mean terjadinya kecurangan laporan keuangan secara signifikan lebih rendah untuk kelompok WHI tinggi daripada kelompok WHI rendah maka $\mathrm{H}_{2}$ didukung $(35,84<39,26)$.
Hasil penelitian ini mendukung penelitian yang dilakukan Sharon Naomi (2015) yang menyatakan bahwa dengan diterapkannya whistleblowing system dapat mengurangi atau meminimalisisr kasus fraud yang terjadi. Hasil penelitian ini juga mendukung penelitian yang dilakukan Vredy Octaviari Nugroho (2015) yang menyatakan bahwa whistleblowing system berpengaruh signifikan positif terhadap Pencegahan Fraud. Dengan demikian maka Mahasiswa Akuntansi UNY akan lebih bertindak whistleblower karena adanya seorangwhistleblower dilingkungannya sehingga menjadikan terjadinya kecurangan laporan keuangan semakin rendah jika menerapkan whistleblowing system.

\section{c) Pembahasan Hipotesis 3}

Hasil pengujian yang dilakukan menunjukkan bahwa $\mathrm{H}_{3}$ tidak didukung karena bystander effect dan whistleblowing tidak berpengaruh simultan terhadap terjadinya kecurangan laporan keuangan. Nilai signifikasi pada hasil pengujian adalah 0,411 . Nilai signifikansi pada hipotesis $>0,05$, yang artinya adanya seorang bystander dan whistleblower tidak memberikan dampak simultan terhadap terjadinya kecurangan 


\section{JURNAL NOMINAL / VOLUME VI NOMOR 1 / TAHUN 2017}

laporan keuangan. Nilai mean terjadinya kecurangan laporan keuangan secara signifikan lebih tinggi dari kelompok BYS*WHI maka $\mathrm{H}_{3}$ tidak didukung $(64,42>20,37)$. Hasil penelitian ini belum didukung oleh penelitian yang terdahulu sehingga hipotesis yang ada merupakan hasil penelitian yang baru dilakukan pada penelitian ini.

Dengan demikian maka Mahasiswa Akuntansi UNY tidak akan bertindak bystander/whistleblower pada saat yang bersamaan karena hanya ada seorang bystander atau whistleblower yang akan dilakukan ketika berada dilingkungannya, sehingga tidak ada hasil yang mempengaruhi terjadinya kecurangan laporan keuangan secara simultan.

\section{Keterbatasan Penelitian}

Terdapat beberapa keterbatasan yang memungkinkan dapat berpengaruh pada hasil penelitian. Keterbatasan penelitian ini adalah sebagai berikut:

a) Variabel independen yang digunakan dalam penelitian ini hanya mencakup bystander effect dan whistleblowing saja, padahal masih dapat ditambahkan dengan variabel yang lain atau dengan variabel intervening.

b) Dalam penyampaian pengisian kuesioner maupun kasus pada kelompok $\mathrm{CG}$ atau $\mathrm{TG}$ dapat menimbulkan perbedaan presepsi karena dalam pernyataan masih terdapat istilah asing terutama pada variabel penelitian bystander effect dan whistleblowing.

c) Penelitian ini masih belum menggunakan pretest dalam menentukan responden kedalam pembagian kelompok $\mathrm{CG}$ atau TG. Pretest dapat mengukur tingkat kecurangan laporan keuangan pada setiap responden.

d) Kurang kehadiran semua responden yang seharusnya pada saat diadakan pengambilan data sehingga responden yang lain menyusul dengan diadakan pengambilan data tambahan.

e) Masih kurang tersedianya penelitian terdahulu tentang bystander effect menjadikan kurang adanya penelitian yang mendukung hipotesis.

f) Responden yang digunakan masih berstatus Mahasiswa Akuntansi UNY. Mahasiswa dijadikan proksi dalam penyusunan laporan keuangan, sehingga hasil yang didapat pada penelitian ini belum mengidentifikasi secara langsung adanya hasil yang signifikan apabila yang digunakan adalah responden yang sudah bekerja langsung dalam pembuatan laporan keuangan di perusahaan. 


\section{SIMPULAN DAN SARAN}

\section{Simpulan}

Dari pengujian tersebut dapat disimpulkan bahwa:

a) Hasil pengujian menunjukkan bahwa bystander effect berpengaruh positif terhadap terjadinya kecurangan laporan keuangan. Hasil nilai signifikansi terjadinya kecurangan laporan keuangan pada bystander effect adalah 0,000 dari kriteria hipotesis diterima adalah nilai signifikansi $<0,05$. Nilai mean terjadinya kecurangan laporan keuangan secara signifikan lebih tinggi untuk kelompok BYS tinggi daripada kelompok BYS rendah $(26,10>23,54)$ sehingga dapat disimpulkan $\mathrm{H}_{1}$ diterima.

b) Hasil pengujian menunjukkan bahwa whistleblowing berpengaruh negative terhadap terjadinya kecurangan laporan keuangan. Hasil nilai signifikansi terjadinya kecurangan laporan keuangan pada whistleblowing adalah 0,000 dari kriteria hipotesis diterima adalah nilai signifikansi $<0,05$. Nilai mean terjadinya kecurangan laporan keuangan secara signifikan lebih rendah untuk kelompok WHI tinggi daripada kelompok WHI rendah $(35,84<39,26)$ sehingga dapat disimpulkan $\mathrm{H}_{2}$ diterima. c) Hasil pengujian menunjukkan bahwa bystander effect dan whistleblowing tidak berpengaruh simultan terhadap terjadinya kecurangan laporan keuangan. Hasil nilai signifikansi terjadinya kecurangan laporan keuangan pada bystander effect dan whistleblowing adalah 0,411 dari kriteria hipotesis diterima adalah nilai signifikansi $<0,05$. Nilai mean terjadinya kecurangan laporan keuangan secara signifikan lebih tinggi dari kelompok BYS*WHI $(64,42>20,37) \quad$ sehingga dapat disimpulkan $\mathrm{H}_{3}$ tidak diterima.

\section{Saran}

Berdasarkan simpulan dan keterbatasan yang ada maka berikut ini beberapa saran yang dapat dipertimbangkan:

a) Bagi Mahasiswa :

1) Tindakan dalam menghadapi adanya bystander effect dan whistleblowing perlu disikapi lebih baik untuk menghadapi permasalahan ketika berada pada lingkungan kerja nanti.

2) Ketika menjadi seorang karyawan yang bekerja di perusahaan dan memiliki atasan/manajer nantinya harus menerapkan untuk menjadi seorang whistleblower walaupun itu sulit untuk dilakukan, tetapi 
seorang yang memiliki integritas, jujur, dan professional akan lebih dihargai dibandingkan seseorang yang hanya menjadi bystander.

b) Bagi Peneliti Selanjutnya :

1) Penelitian selanjutnya sebaiknya menggunakan subyek penelitian yang sudah bekerja dan yang bertugas membuat laporan keuangan di perusahaan (akuntan) sehingga hasil dari penelitian nanti lebih dapat dipertanggungjawabkan.

2) Penelitian selanjutnya dapat menambahkan subyek penelitian pada karyawan yang memiliki kriteria yang lebih luas sehingga mampu mewakili kualitas hasil penelitian, semisal: pengalaman kerja.

3) Penelitian selanjutnya juga dapat mengganti atau menambahkan variabel independen atau intervening untuk mendapatkan hipotesa yang baru.

4) Pada penelitian selanjutnya dapat menggunakan pretest dalam menentukan responden kedalam pembagian kelompok CG atau TG.

\section{DAFTAR PUSTAKA}

A Ivan Sudibyo. (2010). "Pengaruh Kedekatan dengan Korban dan Sikap Bullying terhadap Tindakan Prososial Bystander Bullying di SMA". Skripsi. Jurusan Psikologi Fakultas Psikologi Universitas Indonesia Jakarta.

Albrecht, W. Steve. (2009). Fraud Examination, Fourth Edition. Ohio: Cengage Learning.

Coloroso, B. (2008). The Bully, the Bullied, and the Bystander. New York: Harper Collins.

Correia, I. A., Alves, H., Almeida, T.D., Garcia, D.(2010). Norms regarding secondary victimization of bullying victims: Do they differ according to the victim's categorization? Scandinavian Journal of Psychology, 51, 164-170.

Deni Darmawan. (2013). Metode Penelitian Kuantitatif. Bandung: PT Remaja Rosdakarya.

Elias. (2008). "Auditing Student Professional Commitment and Anticipatory Socialization and Their Relationship to Whistleblowing", Managerial Auditing Journal. Vol. 23, No. 3, 283-294.

Gay, L.R. (1981). Educational Research: Competencies for Analysis \& Application. Columbus: Charles E. Merrill Publishing Company.

Ghozali, Imam. (2011). Aplikasi Analisis Multivariate dengan Program IBM SPSS 19. Semarang: Badan Penerbit Universitas Diponegoro. 
Hair, Joseph F., et al. (2010). Multivariate Data Analysis, A Global Perspective, Seventh Edition. New Jersey: Pearson Education Inc.

Halimah, Andi, Asniar Khumas, Kurniati Zainuddin. (2015). "Persepsi pada Bystander terhadap Intensitas Bullying pada Siswa SMP", Jurnal Psikologi. Vol. 42, No. 2, 129-140.

Hoffman, W. Michael and Robert E. (2008). "A Business Ethics Theory of Whistleblowing". Journal of Business and Environmental Ethics. Bentley Universiy.

Waltham MA. USA, 45-59.

Husein Umar. (2008). Desain Penelitian Akuntansi Keperilakuan. Jakarta: Rajawali Pers.

Hutama, Ponty Sya'banto Putra. (2010). The Influence of the Awareness of the Information on Tax Evasion and Moral Principle towards the Propensity of Tax Easion: An Experimental Study. The Indonesian Journal of Accounting Research (January), 13 (1): 59-76.

Hutama, Ponty Sya'banto Putra. (2011). Pengaruh Pengetahuan Informasi Penggelapan Pajak, Prinsip Moral, dan Penghasilan pada Kecenderungan Penghindaran Pajak: sebuah Eksperimen. Kajian Akuntansi 6 (2): 79-97.

Idhom, Addhi M. (2013). Akibat Korupsi, Uang Negara Meluap Rp168,19 Triliun(online).

http://www.tempo.co/read/news/ 2013/03/04/058464996/Akibat-

Korupsi-Uang-Negara-Menguap$\underline{\text { Rp16819-triliun. Diakses pada }}$ tanggal 6 Januari 2016.
Irham Fahmi. (2012). Analisis Kinerja Keuangan. Bandung: Alfabeta.

Jumingan. (2011). Analisis laporan keuangan. Jakarta: PT Bumi Aksara.

Khan, M.A. (2009). Auditors and Whistleblowing Law. Accountant Today. April 2009, pp. 12-14.

Kloppers, P. 1997, "Behoort die whistleblower beskerm te word?" Stellenbosch Law Review 8(2): 237-248.

Listiana Nobarani. (2012). "Pendeteksian Kecurangan Laporan Keuangan dengan Analisis Fraud Triangle yang Diadopsi dalam $S A S$ No.99". Skripsi. Jurusan Akuntansi Fakultas Ekonomika dan Bisnis Universitas Diponegoro, Semarang.

Lubis, Arfan Ikhsan. (2011). Akuntansi Keperilakuan. Jakarta: Salemba Empat.

Merdikawati, Risti. (2012). "Hubungan Komitmen Profesi dan Sosial Antisipatif Mahasiswa Akuntansi dengan Niat Whistleblowing". Skripsi. Program Sarjana Akuntansi Universitas Diponegoro.

Nur Indriantoro \& Bambang Supomo. (2002). Metodologi Penelitian Bisnis untuk Akuntansi dan Manajemen. Yogyakarta: BPFE.

Prof. Dr. Wmzir, M.Pd. (2008). Metodologi Penelitian Pendidikan: Kuantitatif Dann Kualitatif. Jakarta: PT Raja Grafindo Persada.

Ratna Wardhani. (2012). Faktor-faktor Penyebab dan Konsekuensi dari Kecurangan Pelaporan Keuangan 
(Fraud): Suatu Tinjauan Teoritis. (http://www.bpk.go.id/, diakses tanggal 05 Januari 2016).

Santoso. (2000). Mengatasi Berbagai Masalah Statistik dengan SPSS. Jakarta: PT Gramedia Pustaka Utama.

Sarwono, S., \& Meinarno. (2009). Psikolo gi Sosial. Jakarta: Balai Pustaka.

Sharon Naomi. (2015). "Penerapan Whistleblowing System dan Dampaknya Terhadap Fraud". Skripsi. Jurusan Akuntansi Fakultas Ekonomika dan Bisnis Universitas Lampung.

Sidharta Dasgupta and Ankit Kesharwani. (2010). Whistleblowing: A Survey Literature. The IUP Journal Corporate Governance, Vol IX, No. 4, pp 57-70, October 2010.

Siregar, Syofian. (2011). Statistika Deskriptif untuk Penelitian Edisi Ketiga. Depok: PT Rajagrafindo Persada.

Spathis, T. Charalambos. 2002. "Detecting False Financial Statements Using Published Data: Some Evidence from Greece". Managerial Auditing Journal, Vol.17.

Sukandarrumidi. (2006). Metodologi Penelitian: Petunjuk Praktis untuk Peneliti Pemula. Yogyakarta: Gadjah Mada University Press.

Sugiyono. (2011). Metode Penelitian Kuantitatif Kualitataif dan $R \& D$. Bandung: CV Alfabeta.

Toto Sugiharto. (2009). "Analisis Varians". Modul. Universitas Gunadarma.

Turner, J. L., T. J. Mock, R. P. Sripastava. (2003). "An Analysis of the Fraud Triangle". The University of Memphis, University of Southern California, University of Kansas.

Vredy Octaviari Nugroho.

(2015).

"Pengaruh Persepsi Karyawan Mengenai Whistleblowing System Terhadap Pencegahan Fraud Dengan Perilaku Etis Sebagai Variabel Intervening Pada Pt Pagilaran”. Skripsi. Jurusan Akuntansi Fakultas Ekonomi Universitas Negeri Yogyakarta. 